\title{
Socio-Cultural Constraints in Protecting Child Rights in a Society in Transition: A Review and Synthesis from Oman
}

\author{
Muna Al-Saadoon ${ }^{1} \cdot$ Manal Al-Adawi $^{2} \cdot$ Samir Al-Adawi $^{2}$ (D
}

Accepted: 21 July 2020 / Published online: 7 August 2020

(C) Springer Nature B.V. 2020

\begin{abstract}
In line with international best practice, the Arabian Gulf countries have ratified the Convention on the Right of the Child (CRC), which has some clauses on child abuse and neglect. The present discourse, made from within an Arabian Gulf society, specifically Oman, reviews the socio-cultural differences of the region and explores the potential regional challenges for effectively implementing the $\mathrm{CRC}$ mandated child protection legislation. The international best practices evolved for individualistic, "guilt-based" societies, which may need to be modified to suit the "shame-based" collective societies in the Arabian Gulf where the individual autonomy is overridden by that of the family and society. This may mean that the entire spectrum of child abuse may need to be studied in-depth, starting from what constitutes child abuse and neglect, the methods adopted for identifying cases, setting preventive measures in place, applying penal and corrective action on the perpetrators, and helping the victims recover. It is posited that while modifying the laws may be straightforward, implementation of certain clauses may initially come into conflict with deeply engrained sociocultural conventions on these societies which have different parenting styles and childrearing practices. The country in focus is Oman. Pointing out the sparsity of research on the topic in the region, the study suggests additional research to understand how to reconcile these sociocultural constraints with the international best practices of protecting child rights.
\end{abstract}

Keywords Convention on the right of the child · Children's rights · Social policy · Children at risk - Child indicators across the border · Oman · Arabian gulf region

Samir Al-Adawi

samir.al-adawi@fulbrightmail.org

Extended author information available on the last page of the article 


\section{Introduction}

The protection of children from abuse is a fundamental priority of any modern society. Despite the enactment of laws, policies, and facilities designed to protect the rights of the child, the problem continues to exist. Hillis et al. (2016) have synthesized global estimates on child maltreatment from the available literature and concluded that up to one billion children aged 2-17 years have experienced physical, sexual, or emotional violence or neglect. Moreover, a quarter of all adults may have been physically abused as children. Child maltreatment cases generally present as physical abuse, sexual abuse, emotional (psychological) abuse, and neglect. Consequences include physical injury, impaired cognitive development, mental health problems, suicide attempts, the perpetuation of violence, and death. Vast empirical data suggest that an abused childhood negatively impacts one's adult life (Friesen et al. 2017). Thus, a society's failure to effectively address the maltreatment of its children ultimately affects its socioeconomic health.

In November 1989 the United National General Assembly adopted the Convention of the Rights of the Child (United Nations. General Assembly 1988). As on date almost all countries of the world (including the Arabian Gulf countries) have signed and ratified the convention. CRC describes a child as "any human being below the age of eighteen years unless, under the law applicable to the child, the majority is attained earlier." Many clauses linked to the CRC include access parenting and physical and emotional nurturant, equal protection of the child's civil rights, and freedom from discrimination based on the child's race, gender, sexual orientation, gender identity, national origin, religion, disability, color, ethnicity, or other characteristics. CRC refers to this paper as a blueprint for international best practice and deduces that an individual has an inalienable right to personal autonomy and self-determination/self-governance/ 'self-mastery' (Beauchamp 2019). While the right reserved for minor as depicted in CRC appears to embody the universal standard, it remains to be seen whether the ethos underpinning the child right is equally applicable to societies whose traditions and beliefs regarding the rights of children (Pupavac 2001).

A crucial aspect in the protection of child rights is agreement on a specific definition for child abuse. Several countries, the International Society for the Prevention of Child Abuse and Neglect, and World Health Organization's Consultation on Child Abuse Prevention defines child abuse as "all forms of physical and/or emotional ill-treatment, sexual abuse, neglect or negligent treatment or commercial or other exploitation, resulting in actual or potential harm to the child's health, survival, development or dignity in the context of a relationship of responsibility, trust or power" (World Health Organization 2002). The Centers for Disease Control and Prevention in the USA refers to abuse to as both acts of commission (abuse), which include "words or overt actions that cause harm, potential harm, or threat of harm to a child", and acts of omission (neglect), meaning "the failure to provide for a child's basic physical, emotional, or educational needs or to protect a child from harm or potential harm" (Leeb et al. 2008). United States laws define child abuse as "any recent act or failure to act on the part of a parent or caretaker which results in death, serious physical or emotional harm, sexual abuse or exploitation" or "an act or failure to act which presents an imminent risk of serious harm" (U.S. Department of Health and Human Services 2015). According to the World Health Organization's document World Report in Violence and Health 
(Runyan et al. 2002), physical abuse of a child constitutes overt or potential physical harm subjected to a child. Sexual abuse is defined as those acts where a caregiver uses a child for sexual gratification. Emotional abuse, sometimes labeled as psychological abuse, occurs when a child is subjected to acts that harm their emotional health and development. Emotional abuse often entails non-physical adverse experiences including deprivation, belittling, and derision or threats that have the potential to trigger longterm scars. When a child is deprived of health, education, nutrition, and other essential living amenities, this constitutes a basic indicator of neglect. In the present study, terms such as child abuse, neglect, and maltreatment have been used interchangeably.

Studies from different parts of the world suggest that laws and services to prevent child abuse and neglect are likely to fail if the situation on the ground is not conducive. For example, extreme poverty prevents some Asian and African countries from effective implementation of their child labor prevention laws. In prosperous societies in transition - such as those in the Arabian Gulf including Oman - the resistance is mostly sociological and cultural. Top-down attempts to implement international best practices to improve child protection in all societies without taking into account their ground realities might echo what Kleinman (1987) termed the reification fallacy: blindly implementing a view of human nature developed for one cultural group on another.

In the present discourse, socio-cultural constraints such as the nature and structures of Omani society (authoritarian parenting styles, shame-based social conditioning, collectivist household economies, living with extended family, abhorrence of introspection and expression of emotions) are factors which put children at risk of abuse and may impede the implementation of international best practice. Child abuse and neglect have been often claimed to be amenable to the enforcement of regulations and implementing services are more appropriately disentangled by changing sociocultural factors (Carolina and Gustavo 2003). Many health and social campaigns tend to have only modest success because traditional customs and health beliefs or in the present parlance socio-cultural factors often override biomedical assumptions, the judicial system, and services. Thus, socio-cultural constraints need to be deciphered prior to evolving culturally sensitive strategies to implements international best practices for safeguarding the wellbeing of vulnerable populations in society.

This paper will outline the socio-cultural constraints impacting the protection of child rights in Oman, a relatively prosperous society in transition. These constraints include determining a culturally applicable definition of child abuse, difficulties in determining the magnitude of maltreatment and identifying victims, the differing effects of child abuse, and sociocultural factors impacting the collection of muchneeded data on this epidemic. It is posited that the socio-cultural constraints to enforce child rights evident in Oman would be equally applicable to other similarly situated societies in the region, and would, therefore, prove as useful knowledge for furthering the enforcement of rights of children.

The discourse will initially discuss the state of child protection in Oman through legislation and practice, in the general background of child maltreatment worldwide. The socio-cultural constraints affecting the protection of child rights, with particular reference to preventing child abuse, will then be discussed. The paper will consider how emerging biomedical, legislative approaches and international best practices to safeguard the wellbeing of children might disregard cultural practices, and suggest 
recommendations for the protection of child rights in societies in transition in a culturally specific manner. Oman will be discussed as an example of how sociocultural constraints that a society in transition faces in the implementation of globally recognized practices for child protection.

\section{Differing Effects of Child Abuse}

World Health Organization (2016) estimates that approximately a quarter of adults worldwide have experienced some type of abuse during their formative years, with 1 in 5 women and 1 in 13 men reporting they were sexually abused during childhood. According to Stoltenborgh et al. (2011), there are likely to be $23 \%$ of adults who have been victims of physical abuse as children. The global prevalence of physical maltreatment among children is estimated at $22.6 \%$, emotional maltreatment at $36.3 \%$, physical neglect at $16.3 \%$, and sexual abuse at $18 \%$ for girls and $7.6 \%$ for boys. Most maltreatment occurs during the impressionable ages of infancy and early childhood.

Emotional abuse (sometimes known as psychological abuse), is an amorphous concept, has been given less attention. In general, most emotional disorders referenced in psychiatric nomenclature occur as a result of maltreatment and mostly occur in comorbid forms. Anxiety disorders are commonly associated with maltreatment (Kiser et al. 1991) and may sometimes manifest as post-traumatic stress disorders (PTSD). Acute maltreatment may first present as an acute stress reaction and, if it is the refractory type, it would probably lead to full-blown PTSD (Kiser et al., 1991). Depression is another emotional disorder common among victims of maltreatment (Briere and Elliott 2003). Research among the Saudi population has indicated that adverse childhood experiences may trigger depression and anxiety (Almuneef et al. 2016).

As is often the case, some emotional disorders found in victims of abuse manifest differently across different age groups (Trickett and McBride-Chang 1995). For example, emotional disorders following maltreatment can manifest as reactive attachment disorders or selective mutism among children. The abused may develop learned helplessness or reactivity akin to battered syndrome (Kempe et al. 2013). Among adults, battered syndrome (Walker 2016) can occur where the victim has no provision to seek assistance from others, fight their abuser, or leave the abusive setting (Ford and Briere, 1993).

Overall, traumatic experiences in childhood are strong predictors for dented quality of life and increased susceptibility to indulge in 'self-medication' (Stein et al. 2002). From a psychosomatic perspective, prolonged mental affliction can result in poor physical health outcomes (Norman et al. 2012). Neurobiological studies have indicated that child maltreatment has the potential to halt crucial cognitive and emotional development (Woon and Hedges 2008). A survey conducted in Oman indicated that juvenile delinquency is strongly precipitated by 'maltreatment by significant others' (UNICEF 2010).

Culture can also shape the differences in the expression of emotional disorders among the victims of abuse. Such differences in expression are likely to affect the recognition and treatment of those who have sustained emotional abuse. Many studies among Omanis have indicated that the effects of emotional abuse tend to manifest as 
somatic distress (Al-Adawi et al. 2011) or dissociation (Al-Adawi et al. 2001) risking misdiagnosis. Sometimes dissociation might even be mistaken for epilepsy or psychotic disorders (Al-Sinawi et al. 2008).

In the available literature, child maltreatment has roughly been divided into causing physical, social, and psychological problems (Table 2). The immediate presentation will predominantly be in the form of physical effects. Some of the physical effects heal but emotional scars tend to be long-lasting (Lau et al. 2005). Sometimes emotional problems lie dormant for a while and later re-emerge which, in turn, could trigger physical complaints.

Every year about 31,000 children under the age of 15 are reported to die due to abuse (Sethi et al. 2017). Even this figure may be an underestimation as many child deaths from maltreatment are attributed to accidental causes (Douglas 2016). In the Arabian Gulf States, most perpetrators of child abuse are suggested to be caregivers (Al Ayed et al. 1998). Tradition stipulates that childcare is the prerogative of the parent, and the family is central to individual identity and functioning. Allegations of child abuse affect the honor of the family and are often handled within the family or extended family. Thus, many cases of abuse may not receive the required legal and medical attention (Al-Tarrah et al. 2013). An overbearing judicial system may even have a counterproductive effect according to Baker and Dwairy (2003) who have urged for a culturally-adapted sociological approach to deal with issues of maltreatment. Studies are yet to emerge from the region on how to plan and implement such as strategy.

\section{The Situation in Oman: Status of Children}

In 2010, Oman was ranked as the "most improved nation" in the world in terms of the Human Development Index (HDI) in the preceding 40 years (United Nations Development Programme 2010). During this period, the country's per capita income grew rapidly which in turn caused an unprecedented growth in standard of living leading to material prosperity and a commensurate increase in aspirations among the people. Demographically, Oman appears to be a society in transition and currently at 'stage two' - one that has largely moved away from a 'pre-industrial' state and entered one of modernization and acculturation (Chesnais 1993). The baby boom that began in the 1970s has resulted in the current "youth bulge" where educated young Omanis seek increasingly prosperous and meaningful existences.

Oman fulfilled its Millennium Development Goals in 2015 (National Centre for Statistics and Information 2016), including those having a direct bearing on the wellbeing of youngsters. Having focused on the physical health of children by providing universal access to healthcare (World Health Organization 2008), Oman has witnessed a significant reduction in infant and "under-five" mortality rates: from respectively 118 and 181 per 1000 live births in 1972 to just 9.9 and 12 (Islam 2020). Literacy spread to the most remote corners of the country. The current literacy rate is estimated at $98.7 \%$ among 15-24-year-olds and $35.1 \%$ among senior citizens (>65 years) (UNESCO Institute for Statistic 2020). However, the issues pertinent to child abuse and neglect have received insufficient attention (Al Abduwani et al., 2017) despite anecdotal and impressionistic observations suggesting that Omani society is not immune to child abuse (Profanter 2009; Al-Mahroos 2007; Alshekaili et al. 2020). 


\section{Prevailing Data in Arabian Gulf: Physical Abuse}

The current state of research and reports from Oman and the Arabian Gulf region on child maltreatment is sparse and some of them are reviewed below. Al-Fayez et al. (2012) have explored the lifetime and 12-month prevalence of rate of physical, psychological, and sexual abuse among a stratified random sample of Kuwaiti high school students $(n=4467)$. Approximately $18 \%$ of the participants admitted having memories of at least six occasions of psychological abuse by their parents in the preceding 12 months. Osman et al. (2014) have reported the rate of interpersonal violence among patients hospitalized in Al-Ain, UAE to be 6.7 per 100,000 and $2.66 \%$ of the sample had a history of child abuse. Among the 220 abused children whose records are kept at the Child Protection Centre of King Abdulaziz Medical City, Riyadh, Saudi Arabia, 42\% experienced physical abuse, 39\% endorsed neglect, 14\% were subjected to sexual abuse, and $4 \%$ underwent emotional abuse (Almuneef, Alghamdi, and Saleheen 2016a). In Oman, the cases of 34 sexually abused children - mostly girls from low-income families - suggested that penetrative sexual abuse was strongly associated with depression and disturbed sleep-wake cycles (Alshekaili et al. 2019).

Throughout the Arabian Gulf region, many studies have depicted various forms of physical abuse among children presenting at healthcare facilities (Almuneef et al. 2016b; Al-Mahroos 2007). Physical abuse during maltreatment can lead to bruising, abrasion, bites, burns, torn lips, fractures, retinal hemorrhages and subdural hemorrhage. Hospital-based data is limited by the fact that those who seek medical help are likely to be a self-selective group, presenting severe physical issues. Where parents have induced physical abuse, they are less likely to seek medical help or report the case as an 'accident'. Thus, the prevalence of physical abuse of children in the Arabian Gulf countries remains undetermined due to its furtive nature.

Physically abused children also do poorly at school, as observed by Altamimi et al. (2017) who studied 12-19-year-old students in Riyadh, Saudi Arabia. Another study in a nationally representative sample in Saudi Arabia suggests that adverse childhood experiences have the potential to double the risk of developing diabetes, hypertension, coronary heart disease and obesity (Almuneef et al. 2017). The limitation of this study was that it could not establish the temporal relationship between the cause and effect as is often the case with cross-sectional studies. More studies with robust methodology are needed to examine the magnitude and presentation of physical abuse.

Maltreatment by peers, such as school bullying, is known to impact a youngster's well-being and development. In a preliminary study on Omani children by Fleming and Jacobsen (2009), 38.9\% said they had been bullied in the previous 30 days. Al-Saadoon et al. (2014) surveyed the experience of bullying across 12 months among pupils in Oman, where $76 \%$ of children reported maltreatment by their peers. In a national sample of $13-15$-year-old Omani children $(n=2979), 37 \%$ of girls and $35 \%$ boys reported of having been bullied at least once within the previous 30 days (Al-Saadoon et al. 2014). These studies focused more on the emotional aftermath of bullying.

Regarding the physical impact of bullying among Omani youngsters, Peyton et al.'s (2017) study indicated that physical attacks resulting in "broken bones and dislocated joints, cuts and stab wounds and concussions or other head or neck injuries, being knocked out, or having breathing difficulties associated with an injury" (p. 100) were 
common. An annual incidence rate of 34\% was reported in this particular cohort. According to a study by the Global School-Based Student Health Survey (Peyton et al. 2017), $35 \%$ of girls and $47 \%$ of boys in Oman were estimated to have involved in physical fights in the preceding 12 months.

Additional case reports from Oman include 'shaken baby syndrome' (Koul et al. 2013) and cannabis intoxication (Al-Shidhani and Arora 2011). Al-Saadoon et al. (2012) reported a series of cases of Munchausen's syndrome by proxy, nonaccidental injury, physical abuse by strangulation and sexual abuse. The death occurred in some cases.

Al-Mahroos (2007) scrutinized the literature on maltreatment reported from Oman, UAE, Qatar, Bahrain, Saudi Arabia, and Kuwait for the period January 1987May 2005 and found 222 cases of maltreatment stemming from sexual abuse, Munchausen's syndrome by proxy, physical abuse and neglect. Approximately 3\% of the cases had fatal outcomes.

\section{Prevailing Data in Arabian Gulf: Sexual Abuse}

In Arab countries and the Gulf countries, there is a dearth of studies reporting on child sexual abuse, which is sometimes attributed to the 'culture of silence' in the region. In a recent study, (Almuneef 2019) approximately $21 \%$ of Saudi youth ( $>18$ years of age, $n=10,156$ ) recalled that had been sexually abused during their formative years. The studies also documented an overrepresentation of various chronic medical and psychiatric conditions in those who were sexually abused. The authors also reported that some victims may have succumbed to alcohol and drug use, out-of-wedlock sexual relations and suicidal thoughts." Al-Mahroos and Al-Amer (2011) have documented types of child sexual abuse seeking consultation at the Sulmaniya Medical Complex in Bahrain from 2000 to 2009. Among 440 children, $38 \%$ had been sodomized while genital touching and fondling were reported in the majority of the cases.

Al-Eissa et al. (2016) screened 15-19-year-old Saudi adolescents $(n=16,939)$ for incidents of violence, psychological, physical and sexual abuse, and neglect. ISPCAN Child Abuse Screening Tool was used for data collection. The previous year's occurrence of violence exposure, psychological, physical and sexual abuse, and neglect were assessed. The presence of various types of maltreatment ranged from 0.10 to 0.65 according to the criteria defined by the ISPCAN Child Abuse Screening Tool. Psychological abuse was highest, while sexual abuse was least endorsed.

The above reports indicate that abuse is prevalent in Oman and the region, however, there remains a lack of large-scale reliable data on abuse such as those produced by the World Health Organization. The type of abuse studied, the coverage and quality of official statistics, and the coverage and quality of selfreported surveys from victims, parents, or caregivers are some of the potentials confounds leading to poor quality data on maltreatment (World Health Organization 2016). 


\section{Socio-Cultural Factors and Data Child Abuse}

The aforementioned discussions have highlighted prevailing data in Arabian Gulf on physical abuse, emotional and sexual abuse. The prevailing data is likely to be the 'tip of the iceberg' as been indicated in studies carried out in other populations (Klika et al. 2020). In this section, the focus is on certain socio-cultural factors that make it difficult to elicit information on matters like child abuse in Oman. Some of these factors are considered below.

The first and foremost if the issue is that of taxonomy. The clear consensus is yet to be arrived on what constitutes child abuse or neglect in scientific, yet culturally sensitive terms. Without a clear definition, victims or family members of the victim would be unsure when to report, law enforcement officials would struggle to categorize situations as constituting abuse, and even researchers would face obstacles in gathering data if they are unclear on what definition to apply. There is also a risk of different researchers applying conflicting definitions or definitions based on value judgments, thus reducing confidence in reports from the region.

Under-reporting of cases of child abuse and neglect can be expected in any society, however, it is even more likely in shame-based societies, where concepts such as pride and honor prevail (Wikan 1984). As is often the case, anything deemed shameful by bioethical practice or the judicial system is likely to be socially ostracized behavior, and therefore such behavior would remain furtive. For instance, disclosing female sexual abuse in Arab countries risks desecrating the honor of the families and the social future of the victims. To adequately determine the magnitude of such cases of sexual abuse, there is a need for culturally sensitive policies that consider the socio-cultural constraints on reporting.

In collective societies such as those in Oman, individual identity strongly hinges on the family and therefore reciprocity and interdependence are critical factors to consider. Thus, the family rather than the state is perceived to be central in safeguarding the wellbeing of the individual (Baker and Dwairy 2003). As long as the livelihood of victim and perpetrator are part of a symbiotic system, it is very difficult that the case is conveyed to the judicial system (Baker and Dwairy 2003). In such an enmeshed society, for cases of child abuse get reported, there must be extraordinary moral conviction and courage on the part of the victim's family and supporters place his/ her well-being and rights above family honor and shame. There should be a mechanism to support such pioneers. Being shamed must shift from the victim and his/her family to the perpetrator of the abuse. However, for these attributes to infuse into the social consciousness in Oman, the definition and seriousness of various types of child abuse must be unambiguous and known to both children and adults.

While the functioning of society in its relationship with the wellbeing of children needs to be empirically explored, the magnitude of child abuse also needs to be established. It is well known that the available statistics represent but the tip of the iceberg. Paine and Hansen (2002), in their comprehensive review of the factors influencing children in Western culture to self-disclose sexual abuse, pointed out that stated that: "...children raised within cultures espousing collectivistic values may be more hesitant to disclose their abuse due to heightened concerns regarding the negative impact such disclosure will bring upon their family and ancestors" (p. 275). In their view the second critical factor related to disclosure is the "victim-perpetrator 
relationship' and whether the abuser is a member of the child's family, an outsider known to the child, or a stranger. A third factor is the abusers' tendency to select and groom their victims according to their temperaments. Children with timid personalities and those without effective caregiver supervision are often preferred. Unable to confront the abuser directly, the child's 'impetus for disclosure' may stem from a desire to stop the abuse. The child may gain further impetus to disclose if the perpetrator confesses, is criminally convicted, or medical evidence of the abuse is available (Paine and Hansen 2002).

Research is lacking from the Arabian Gulf region regarding disclosure in relation to child maltreatment specific to such societies in transition. Such information is crucial in the protection of child rights, as understanding the factors that could increase the magnitude of abuse would lead to more effective policies and practices to intervene or prevent the same from happening. Several factors are likely to exacerbate child maltreatment in the Arabian Gulf. These are highlighted below with specific attention to (a) lower intellectual and social competence and cognitive ability in the child, (b) family structure and household composition including reliance on domestic workers in child-rearing.

The Global Burden of Diseases, Injuries, And Risk Factors 2015 (Global Burden of Disease Child and Adolescent Health Collaboration 2017) show that population growth and improved medical care in countries such as Oman have significantly increased the number of children with who manifest physical, social and cognitive impairment. Overall, Oman's population is characterized by large family size and consanguineous marriage which is believed to link to several developmental abnormalities including those that lead to life-limiting diseases (Islam 2012; Woodley 2009). A plethora of studies has indicated that children with disabilities are often targeted for maltreatment. Children with mental retardation and behavioral disorders are more prone to maltreatment compared to their typically developing peers (Browning and Boatman 1977). Jones et al. (2012), in their systematic review and meta-analysis data of 1990-2010, estimated that children with disabilities had approximately $27 \%$ higher risk for sexual and other abuse. Children with disabilities also are even more vulnerable to sexual violence (Paine and Hansen 2002). Thus, with increased population growth in societies in transition, there is also likely to be an increased number of "children-at-risk". Studies in Oman are needed to document the types and magnitude of maltreatment, if any, among children with disabilities.

\section{Some Risk Factors for Maltreatment of Children}

Studies have suggested that family income strongly predicts the vulnerability of children to maltreatment. For example, infant homicide is reported to be highest among low-income groups (Ward and Viner 2017). It is not clear whether the link between income and magnitude of child abuse could be generalized to the situation in the Arabian Gulf countries, as they are categorized as 'high income' by the World Bank. While few Omani families can be classified destitute, wide disparities in income exist. Alshekaili et al. (2019) have reported that sexually abused children have so far consisted of those children likely to belong in the lowest brackets of household income. Zielinski (2009) indicated low socioeconomic status to be a critical risk factor for child 
maltreatment, one reason for which may be the continuation of the intergenerational transmission of abuse which may have been more prevalent during widespread poverty in the region which was the norm till about two generations ago. The recent affluence may not sufficiently heal the old scars of poverty and want which may be felt more by people who find themselves poorer compared to the general society. Studies are needed to shed light on how inequalities in income and opportunities for social mobility affect children and render them vulnerable to abuse.

Recent affluence and increased standard of living in Oman have brought many women into the labor force. Regardless, Omani society still has a high birth rate (Dorvlo et al. 2006) though more recently there is a gradual decline (Roser 2020) Overall, women in Oman have experienced increased socioeconomic empowerment through employment, but they are concurrently expected to fulfill the traditional role of mother (Amzata et al. 2017). In terms of child-rearing practices and bonding between child and caregiver in the Arabian Gulf countries, there is evidence to suggest that women's divided attention between their traditional roles of 'homemaker' and member of the workforce (Belwal and Belwal 2017) may affect the quality of parenting. It may be posited that the increase in women's economic participation without simultaneous changes in the division of household tasks results in work-family conflict and increased stress in the household (Cerrato and Cifre 2018). While not trying to dump the muchdesired women empowerment, studies are needed to shed light on the trajectory of women in the labor force.

With rising disposable income, many households in Oman rely on expatriate Asian and African domestic servants (Mansour 2017). While the mother is away at work, the servant assumes charge of the baby in addition to their domestic work, thereby increasing the likelihood of maltreatment (Al-Mahroos 2007). In addition, reliance on domestic workers may lead to proximal abandonment whereby parents are not available to provide the required emotional nurturing for their children (Tang 2008). The reliance on domestic help to rear children would require empirical scrutiny in the region along with its relationship to a child's vulnerability to maltreatment if any. This has the potential to lay the groundwork for evidence-based prevention of child abuse and neglect.

As with differences in child-rearing practices in societies in transition, the structure of families and the composition of the household may differ and thereby have an impact on the prevalence of abuse. Some studies have examined whether sexual abuse is likely to occur within a family (intrafamilial) or outside the family (extrafamilial). The data gives more weightage to intrafamilial, specifically, males with authority over the children and proximity to them being the most common. Fathers and stepfathers have been found to commit approximately $7 \%$ of cases of child sexual abuse. Uncles or older siblings as the perpetrators of sexual abuse has been estimated to constitute approximately 16-42\% of child sexual abuse cases (Sadock and Sadock 2007). In extrafamilial sexual abuse, adults in positions of authority such as teachers, clerics and sports coaches have been implicated. Children living in single-parent households have a higher risk of being sexually abused. Children living in extended families may also be at a higher risk of abuse. Contrary to anecdotal public perception, strangers constitute a lower risk of child abuse. There is however a lack of research on the effect on child abuse in close-knit collective communities - as is usually the case with society in transitions such as Oman - as opposed to living in less tight-knit communities 
characterized by nuclear families as seen in most societies in North America and Western Europe.

In addition to children with disabilities, there is also an indication that children with special talents may also fall prey to maltreatment. With the increased focus on education in the Arabian Gulf, there is recognition of the increasing number of children who might be categorized as having special needs or talents, or different skill sets compared to their peers (Gelbeheri et al. 2009; Al-Mannai and Everatt 2005). Such children tend to be social outliers and be emotionally sensitive with less tolerance to criticism, punishments and bullying (Cross and Mendaglio 1994, Edmunds and Edmunds 2005). Intellectually gifted children may think differently, refuse to learn by rote, be individualistic and less culturally adaptable, become easily bored and sometimes disrupt the class. Society may respond by snubbing, shouting, resorting to corporal punishments, or social isolation. Such children may face more difficulties in collective societies that seek to "standardize" child behavior more compared to individualistic societies. While most children may take such punitive measures in their stride, the "outliers" may find such collectivistic methods of disciplining intolerant and may develop emotional problems (Kim 2013). Gifted children may emerge from any region of Oman including rural areas, where they may face multiple barriers to achieving their potential including the extreme traditional orientation of the rural societies and reduced reach of educational reforms and initiatives. Studies are therefore needed to examine how best to safeguard the wellbeing of children with scholastic problems.

\section{Child Protection in Oman}

Oman has enacted both international and local legislation focused on the rights of the child. Oman ratified the Convention on the Right of the Child (CRC) stipulated by UN in 1996 (and the two Optional Protocols to the Convention "involvement of children in armed conflict" and "sale of children, child prostitution and child pornography" in 2004). The National Committee for Family Affairs was established to monitor the implementation of CRC articles. As a result, many policies and programs relevant for the wellbeing of children came into being (Table 1), including Oman's Child Law which was issued by Royal Decree No.22/2014 on May 19, 2014 (UN Committee on the Rights of the Child 2015).

\section{Government Policy \& Initiatives}

Following the issuing and amendment of the above-mentioned legislation, the concerned authorities implemented strategies and action plans to protect and support victims of child abuse in Oman (General Secretariat of the League of Arab States 2010). Since 2007, the Ministry of Health gathers information on suspected incidents of violence against children presented at health facilities across the country (UN Committee on the Rights of the Child 2015). The National Commission for Family Affairs and Ministry of Social Development have formulated teams to study and follow-up on cases of children at risk of abuse, initiating 
Table 1 Main features of legislation in Oman addressing the specific needs of the child in Oman (UN Committee on the Rights of the Child 2015)

Royal decrees

(a) A Statute of the National Committee for Family Affairs, Royal Decree no. 12/2007

(b) Juvenile Accountability Act, Royal Decree no. 30/2008

(c) Care and Rehabilitation of the Disabled Act, Royal Decree no. 63/2008

(d) Trafficking in Persons Act, Royal Decree no. 126/2008

(e) Cybercrime Act, Royal Decree no. 12/2011

(f) Amendment of the Labor Act 35/2003, Royal Decree no. 113/2011 granting working women special maternity leave of 50 days

Ministerial decisions

(a) Statute regulating family care and fostering, Ministerial Decision no. 49/2007;

(b) Statute of public school student affairs, Ministerial Decision no. 105/2012;

(c) Statute regulating camel racing, Oman Camel Racing Federation Decision no. 7/2009

(d) Determining places of child visitation, Minister of Justice Decision no. 271/2006

(e) The statute regulating the Juvenile Reform Home, Ministerial Decision no. 126/2010

(f) Statute regulating the Childhood Care Centre, Ministerial Decision no. 125/2009

a proper training program that qualifies all those concerned, with the skills required to provide appropriate services for victims and their families (UN Committee on the Rights of the Child 2015). As a result of such initiatives, there are anecdotal reports suggesting good coordination between the various governmental institutions including the Ministry of Social Development, Ministry of Health, Ministry of Education, Ministry of Legal Affairs, Ministry of Justice, Ministry of Manpower and the Royal Oman Police (UNICEF 2010).

The Ministry of Social Development and UNICEF also produced a manual of guidelines to manage victims of child abuse with the aim of improving and standardizing the services provided to them (UN Committee on the Rights of the Child 2015). Special protection measures are also provided to specific groups such as employed youth who are below the age of 18 years, children in conflict with the law, children of incarcerated parents and children living in prison, and children without parental care (UN Committee on the Rights of the Child 2015). To improve reporting and rehabilitation services provided to child abuse victims, in 2012 the Ministry of Social Development, through its Family Protection Department, set up a welfare and rehabilitation home (UN Committee on the Rights of the Child 2015). In 2016, a child protection hotline (1100) was launched (UNICEF 2010).

Oman has recognized the need to increase knowledge and raise awareness regarding child maltreatment through direct work with children, parents, guardians, teachers and all those providing child care and supervision to promote positive relationships within a safe environment. Primary prevention through the establishment of educational programs to train caregivers on good parenting and life skills, increasing awareness among individuals about children's rights, and educating the public regarding child abuse consequences would be important measures in this direction. This usually leads to earlier reporting of abuse cases thereby ensuring more effective intervention (Kenny 
2004). In Oman, awareness campaigns, television and radio programs, annual children's festivals, and local forums are conducted to emphasize child rights and raise awareness about measures and mechanisms to protect children (UN Committee on the Rights of the Child, 2015). Concerned authorities have also implemented training programs for professionals working with children on the topic of children's rights and issued policies pertinent to accessing remedial and rehabilitation services for the victim (UN Committee on the Rights of the Child, 2015).

In addition, remedial and social support services have been put in place through the Ministry of Social Development. For example, the Ministry of Social Development has sought to empower women by opening "Women Associations" in different parts of the country. Within the 60 branches of Women Associations, child nurseries have played an integral part in this initiative. Under the Ministry of Social Development entitled 'Directorate of Family Counseling' provision of support to vulnerable families has also been instituted. The response and support services have also been extended to include rehabilitation services to juvenile delinquents and their families.

\section{The Challenge of Implementing International Best Practice}

Although international bodies such as the World Health Organization and Centers for Disease Control and Prevention have posited definitions of child abuse and neglect, there is no universally accepted definition with interpretations varying depending on the culture. Some of the child-rearing traditions that international best practices deem to be "child abuse" might be perceived as benign and culturally warranted in some traditional cultures such as Oman. For example, socialization training in Oman bears resemblance to what cultural anthropologists, such as Benedict and Gennep (1978 have called, 'shame-based' or 'honor-shame' culture ). In contrast to cultural patterns that are 'guilt-based, shamed-based cultures tend to use shame and honor to shape child conformity. Parents within shame-based societies practice an authoritarian style of parenting (Mintz et al. 2017) which requires the children to strictly adhere to the directions of the parent (Al-Adawi 2006). Corporal punishment is one of the extensions of such child-rearing practices (Alizadeh et al. 2007). Indeed, spanking and to some extent shouting is often viewed as a form of discipline and an integral part of filial obedience (Al-Belushi 2004). However, some of these would be classified as maltreatment according to international best practices. Further, due to the inherent tendency for shame-based societies to encourage conformity, some anecdotal reports from Oman have suggested that children who are not conforming to required social prescriptions are subjected to maltreatment (Profanter 2009). A study in Kuwait has indicated that the majority of parents harbor the view that physical punishment is benign and essential to shaping good behavior (Qasem et al. 1998).

An extreme example of the socio-cultural impact on defining child abuse is that of female genital mutilation (FGM) or female circumcision. What is deemed as child abuse in many cultures could also be viewed as a 'rite de passage' in the case of FGM (Althaus 1997). According to international best practice, FGM is a form of violation of rights and therefore should be viewed as a form of abuse. Even though female circumcision is banned in hospitals in Oman, maps that depict the worldwide practice of FGM continue to show a large number of cases in the country. According to Al- 
Hinai (2014), "female genital mutilation constitutes a widespread phenomenon in Oman in all age groups, and among women from all regional and educational backgrounds." Conceptually, FGM constitutes the penultimate form of child abuse (Barstow 1999). However, the local practice may view FGM differently, and in fact, such view varies even within groups in the same country or city.

Just as there is no universal definition of child abuse, there remains no universal consensus for optimal child-rearing. Child-rearing practices of a collectivist society as in Oman may conflict in some ways with the western "individualism" based on the philosophical principles of respect for persons and the emphasis on individual autonomy (Baker and Dwairy 2003). In this regard, it is worthwhile to note that international best practices to safeguard the child's rights are based on a western, bioethical approach which often accentuates the importance of individualistic values. Oman, having been exposed to rapid globalization, has had to walk the fine line between its cultural practices and emerging hegemony of western bioethics in biomedical practice and judicial system.

Studies from the region have suggested that consideration for individual autonomy is increasingly gaining a foothold. Studies among pediatricians and parents in Kuwait suggested that the 'new generation' seems to be regarding what is entailed in shamebased child-rearing practices as being atavistic and should be abandoned (Qasem et al. 1998; Al-Moosa et al. 2003). A similar endorsement was reported in Saudi Arabia (Alnasser et al. 2017; Mogaddam et al. 2016), UAE (Hashim and Al-Ani 2013), Qatar (Eldeeb et al. 2016), and Bahrain (Merza et al. 2013).

\section{Challenges and Recommendations}

As explained above, what constitutes "maltreatment of children" in legal and biomedical settings in individualistic societies of the world does not always coincide with the socio-cultural orientation and values of the collectively oriented Arab societies. This hampers the introduction of international best practices to safeguarding the wellbeing of the children in countries like Oman. In the past decades, the Arabian Gulf economies such as Oman were able to channelize their petroleum-based revenues towards rapidly modernizing their economies, enabling their populations to reach living standards comparable to those of the developed world. Along with higher health and educational standards, these countries also rapidly connected with the rest of the world, causing a massive change in the outlook and aspirations of the people, particularly the youth. (Sandwick 2019). At the societal level, there is evidence to suggest that the spread of modernity may have some echoing to the concept 'anomie' postulated by Durkheim (1997) whereby the individual member may find little sense of belonging in their society. According to Al-Barwani and Albeelyb (2007), there is a public concern for the "weakening of family ties" in the region due to growing female employment and urbanization. The empowerment of women in some of the GCC countries, for example, Oman has opened the door for Omani women to join the workforce, leaving their children to be tendered by expatriate maids. Omani children are increasingly left on their own as mothers and other adult women in the family work away from home, thus setting the background for 'proximal abandonment' (Al-Adawi 2014). According to Atiyyah (1996), 'a working wife... is not the most important reason for hiring a 
domestic servant.' Amidst the reports of foreign domestic workers being abused in the region (Parreñas 2015), there are also indications that some of them abuse the children under their care (Al-Mahroos 2007). Thus, the tussle between rapid female empowerment and the thousands of years of tradition which insists that girls and women should be homemakers is impacting Omani family life, particularly its children.

It remains to be seen whether social changes due to ongoing acculturation would soften the existing collective socio-cultural traditions (Silvey 2006) and shift Omani social attitudes towards tolerating more individualism. In such a scenario there may be reduced resistance to the international best practices based on individual autonomy to promote the welfare of children. However, if the collective identity continues to hold sway, alternative strategies within that constraint need to be contemplated to reduce child maltreatment in Oman.

A major constraint towards evolving such strategies is the scarcity of data on the nature and prevalence of child abuse in Oman. There is also a dearth of studies that have audited the functioning of the existing services equipped with biomedical, legislative approaches and international best practices for safeguarding the wellbeing of children in Oman. Most literature pertinent to child abuse and neglect is limited to cases of extreme maltreatment which necessitated medicolegal attention and documentation. These may include egregious cases related to sexual abuse (Alshekaili et al. 2020), abandoning a child after an unwanted pregnancy, or the spectrum of Munchausen syndrome by proxy (Al-Saadoon et al. 2012). Meanwhile, there is possible that socio-cultural constraints prevent much subtler yet debilitating forms of child maltreatment from reaching the scrutiny of biomedical care or the judicial system. Baker and Dwairy (2003) have suggested adopting a culturally sensitive approach to overcome some of the socio-cultural constraints. In the ensuing paragraph, some of the issues that would require contemplation to come to grip with a child with an emerging consenting view - traditional vs international best practice towards coming to grip with child maltreatment. The following points are therefore worthwhile to consider including (i) increasing the awareness in the society of what constitutes child maltreatment, (ii) establishing relevant taxonomy for child maltreatment, (iii) identifying the type and magnitude of child maltreatments, (iv) spreading the services relevant for child maltreatment, (v) devising preemptive measures, (vi) decipher Omani culture microsystems, (vii) ensuring culturally sensitive justice for the victims, and (viii) conceiving culturally sensitive interventions.

\section{Awareness}

While in Oman's vernacular depiction, children are God's greatest gift (Al-Adawi 2006), mechanisms are needed to propagate awareness toward child maltreatment. Such an initiative should be geared towards targeting all strata of society. In school curricula, child maltreatment only received only scant attention. Studies have indicated that teachers' possessing suboptimal knowledge regarding child abuse and reporting procedures, and many did not receive training in child abuse identification and notification. This occurs despite the fact that teachers are potentially the 'first line of defense' in identifying and preventing child maltreatment (Kenny 2004). The response and attitude of law enforcers towards child abuse is also crucial, but one study from Hong 
Kong has suggested them having an ambivalent view of child maltreatment (Cheung \& McNeil Boutte-Queen, 2000). In addition to the teacher and police, medical education should receive optimal exposure to issues pertinent to child maltreatment and all its forms. Lack of familiarity with the signs and symptoms of maltreatment makes it extremely difficult to report suspected abuse causing unnecessary delays in the identification of victims (Kenny 2004). To society as a whole, education should dispense that child maltreatment is a punishable act and to report maltreatment is lawful right or duty. The victim has a lawful right to report the maltreatment. On the part of the authority, it might be essential to release the magnitude and the type of maltreatment in the society without stigmatizing the victims.

\section{Taxonomic}

Mechanisms are needed to establish a culturally appropriate classification of child maltreatment. An absence of a culturally agreed-upon definition of child abuse and neglect hampers the detection of abuse and the determination of its magnitude and therefore poses an impediment to the adequate protection of child rights. Indeed, taxonomic assumptions have the potential to shape the views of psychopathology, treatment and administrative decisions, professional communication, formal diagnoses, diagnostic formulations, research, epidemiology, and public policy (Mathews 2019). Laws cannot be properly enforced and awareness or training will be sub-optimal if there is cultural disagreement on the fundamental question of what is child abuse and neglect? If this hypothesis is true, future studies need to decipher effective ways to recognize distress in victims of maltreatment without having to undo idiosyncrasies of the culture within which the victim resides (Al-Adawi et al. 2011). Imposing global definitions of child abuse without taking into consideration socio-cultural factors would create significant issues for law enforcement professionals. For instance, if using spanking to discipline a child was deemed "abuse" in a society such as Oman, then a majority of families would then be categorized as abusers. It is therefore essential to begin the standardization of taxonomy relevant to child abuse if legislation and practices on child rights are to be effective.

\section{Identification}

Compared to children in Western Europe and North America, children in societies in transition (as those in the Arabian Gulf) tend to report fewer experiences of maltreatment (Dwairy and Menshar 2006). One possible reason for this might be the lack of awareness and services for child maltreatment in the region. Another possibility is the 'culture of silence' whereby family or the victim of child maltreated children tend to keep their negative experiences - particularly those occurring within the family private. Studies from different parts of the world indicate that intrafamilial child abuse is much more frequent and perpetrated on younger children compared to extrafamilial abuse which tends to be fewer, and mostly affects older children (Al-Mahroos 2007). Thus, we may expect that children may be much less forthcoming about their 
intrafamilial abuse experiences, which resonates with the view that child maltreatments are likely to remain furtive (Mathews 2019).

The identification of child maltreatment is likely to be marred by the tip-of-theiceberg phenomenon (Al-Mahroos 2007), where subtler and deeper socio-cultural factors further hamper identifying the victim of child maltreatment. Most research on child abuse has been conducted on guilt-based societies of the West. There is evidence that cultural conditioning in shame-based societies due to maltreatment may cause distress to be manifested in culture-specific signals. For example, the tendency to experience emotional discomfort as somatic distress is higher in Oman and Arabian Gulf region than in the West. There may be other signals that remain unknown. Thus, research in Omani and other Arabian Gulf societies should seek to decipher whether the symptomatology of the sequel of maltreatments or distress such as those that have been reported in western psychiatric nomenclature have heuristic value in societies in transition under scrutiny here. Identification of such symptomatology will help evolve region-specific instruments to measure the presence of child maltreatment in the Arabian Gulf countries, which have mostly employed instruments with items directly borrowed from the trend in the with international best practices (Al Abduwani et al. 2017). Even though the screening measures were judiciously translated into the local language, some of their ability to identify child abuse could be hampered by not asking the right question, not to speak of the subtle linguistic and conceptual misunderstandings which are possible during translation to Arabic (Mathews 2019). Therefore, underrecognition is likely to be common. Therefore, qualitative studies need first to establish the idioms relevant to child maltreatment in the region which, in turn, would generate more reliable instruments to identity local idioms of child maltreatment. These instruments can thereafter be employed in the next level qualitative or mixed methods studies that address and deal with the problem of child abuse with more effectiveness.

\section{Distribution of Services}

As awareness would likely improve with the enactment of child laws, Oman would need to avoid the difficulty that has persisted in other societies in transition where the services and amenities for victims are located entirely in urban areas (Obosi 2019). While laws and policies are best evolved in a centralized manner, most implementation - except tertiary care - need to be decentralized, and made region - and subculturespecific. This is to avoid the affected child or family having to visit different institutions to receive the required child protection services due to the lack of centralization of services within one institution. The equity of services to all regions would be paramount. Some services, such as forensic medicine services and pediatric psychiatry, are still only available in the capital region of the country (Alakhzami and Huang 2020). Such long distances may deter victims and caregivers from seeking specialized help. Currently, the services are either biomedical or judicial. Efforts are needed to trains and equipped cadres of Omani with the skill for prevention and overseeing the wellbeing of the children. The strata of the society should be imparted with the awareness that child maltreatment is not the domain of one 'specialty' but 'everybody's businesses. The existing fragmented services in Oman would need to be rehauled. 


\section{Prevention}

One limitation of the present child protection system is that it is geared towards helping children who are already been 'harmed' (Hart and Glaser 2011). World Health Organization and International Society for Prevention of Child Abuse and Neglect (2006) pointed out that most child protection and law enforcement agencies who have been assigned preventive responsibility "may have the limited professional capacity and lack the mandate to influence policy on prevention or to address the many risks and protective factors. As a result, the prevention of child maltreatment tends to be addressed as if it were synonymous with child protection and victim services" ( $p$. 33). In the Arabian Gulf countries, Al Midfa et al. (2019) surveyed the readiness for the prevention of child maltreatment among key stakeholders. Along a readiness scale of 0-100 (higher score denoting optimal readiness), the study found stakeholder readiness scores of 47.8 which the authors defined as moderate-to-fair readiness. However, this study had a drawback in that it included the key stakeholders. More external studies are needed to explore how to prevent child maltreatment in all strata of the Arabian Gulf societies. Overall, there is much to be defined to define prevention and how to go about it. Oman has to avoid falling into such a pitfall where prevention is often relegated to the backburner. It must be remembered that Oman is a collective, honor-shame-based society where victims and witnesses of child abuse less likely to be forthcoming. This causes the actual instances of abuse to go under-reported, and the vulnerability to be abused is even less identifiable. According to Scruton (2000), "the real purpose of shaming is not to punish crimes but to create the kind of people who don't commit them" (p. 71). The practical utility of such claims needs to be verified by in-depth and extensive qualitative research, which is still lacking in the region.

\section{Pre-Emptive Education}

As most child maltreatment emanating from the region appears to be predominantly intrafamilial (Alshekaili et al. 2020), it is likely that the caregivers in Oman genuinely perceive themselves as fulfilling their obligation to pattern their children according to their socio-cultural teaching to bring them up as competent members of the society (Bake and Dwairy 2003). Thus, parenting is strict and modeled with authoritarian structure (Bake and Dwairy 2003) and filial obedience on the part of the children is highly reinforced in Oman (Albelushi 2004). Similar socialization exists in Asia and some time is labeled as 'tiger parenting' (Kim 2013), reminiscent of dictums such as 'spare the rod and spoil the child' where corporeal punishments are considered part of filial obedience (Al-Belushi 2004). Thus, such sociocultural teaching is likely to perceive discipline as paramount for 'good upbringing'. This, in turn, is likely to present a challenge to emerging international best practices. Therefore, a concerted effort should be taken impart awareness in the society that 'disciplining' the child sometimes lead to detrimental effect. Efforts are needed to raise awareness of the sequelae of psychological, physical and sexual abuse on the child, and its long-term impact on the family status and honor. Related to this, a study from the region has suggested that most child maltreatment are often perpetrated by overambitious, frustrated, or depressed mothers (Douki et al. 2013). Culturally sensitive health education 
should be contemplated to address the stress among the parents. Motivated groups such as the Oman Women Association (an initiative of the Ministry of Social Welfare scheme), could be encouraged for educating the mothers on the detrimental effects of harsh disciplinary practices. Case histories from different parts of the world might be presented along with the long-term impact of abusive disciplining.

\section{Decipher Omani Culture Microsystems}

The prime way to shed light on our unfamiliarity with the Omani familial microsystems is to conduct qualitative studies in the community. The research needs to encompass the microsystems, but emerge with evidence-based information on the total 'ecosystem' defined as 'the world of the parents' work, the neighborhood, and social support systems' by Itzhaky and York (2001). Finally, as it has been widely established, human experiences are shaped by socio-cultural patterning. Thus, the microsystem that Itzhaky and York (2001) have called the larger cultural fabric, would need to be understood so that an informed view could be contemplated. For example, child-rearing practices or parenting styles in collective society as those in Oman are likely to fall under the category of 'authoritarian parenting styles', which are known to be relatively rigid and strict, wherein corporal punishment is widely practiced and the teaching that 'if one does not discipline a child, he or she will never learn obedience and good manners' prevails. Therefore, if emerging legislation on child abuse may need to opt to keep a considered middle-way been the international best practices and Omani sociocultural norms, based on ethnographic qualitative research conducted among families in different parts of Oman. As Omani society becomes accultured, the child protection laws could be gradually updated to match such change. This implies that an ecological integrated model of child maltreatment needs to be orchestrated to all strata of society. According to Itzhaky and York (2001), such undertaking should include issues pertinent to "ontogenic development," defined as a physical, cognitive, emotional, and social development that can be attributed to experiences with the environment and the individuals within that environment. Within the society, the family including characteristics of the abused child, the spousal relationship, and sibling relationships (known as a 'microsystem') needs to be brought on board to further discourse on prevention and intervention for children who are prone to child abuse.

\section{Justice to Victim}

The question remains on how to ensure justice to the victim and correctional (rather than retributive) penalization on the perpetrator. However, the path towards these is made complicated by the collective and shame-based nature of Omani society, as opposed to the Western societies which are often seen as individualistic and "guilt-based." Most of the clauses in the international best practice were evolved to suit "guilt-based" societies based on western philosophical principles of respect for persons and with a strong emphasis on individual autonomy (Al-Saadoon and Al-Adawi 2019). In traditional Oman society, one's identity depends on one's bloodline mainly via paternal ancestry. Married women keep their father's name and thus his ancestry. The same identity is shared by many other members of 
the individual's extended family. Thus, Arab children grow up experiencing the importance of how their elders maintain family honor and protect it from shame. Generation after generation these concepts have been used to enforce social patterning (Wikan 1984). For these reasons, Baker and Dwairy (2003) suggested that the power of shame and honor could be used to address child maltreatment: “... a family's reputation is among the most important resources of an Arab family. A negative reputation may be attached to a family after cultural or religious misconduct." All extended family members bear the consequences of misconduct, which could range from social shaming to full socio-economic boycott. Thus "whistleblowing" from within the family may end up causing serious and long-term collateral damage for both the whistleblower and the family. Thus, it is not clear how the utilization of shame in tandem with the judicial system might be effectively used to reduce the prevalence of child maltreatment in Oman. Studies to address this issue are therefore warranted.

Table 2 Example of the suggested temporal relationship between childhood adversity and cadre of physical, social and psychological problems

\begin{tabular}{|c|c|}
\hline \multirow[t]{5}{*}{ Physical } & Abdominal/thoracic injuries (Kotch et al. 1993) \\
\hline & Acquire brain injuries (Buchweitz et al. 2019) \\
\hline & Bruises, welts, lacerations, and abrasions (Alexander et al. 2001) \\
\hline & Fractures (Felitti 1998) \\
\hline & Eyes injuries (McBeth et al. 1999) \\
\hline \multirow[t]{4}{*}{ Sexual and reproductive ill-health } & Reproductive health problems (Cooperman and Merten 2001) \\
\hline & Sexual dysfunction (Rapsey et al. 2019) \\
\hline & $\begin{array}{l}\text { Sexually transmitted diseases, including HIV/AIDS (Shamu et al. } \\
\text { 2019) }\end{array}$ \\
\hline & Unwanted pregnancy (Hall et al. 2019) \\
\hline \multirow{10}{*}{$\begin{array}{l}\text { Cognitive, emotional and behavioral } \\
\text { disorders }\end{array}$} & Developmental delays (Croft et al. 2019) \\
\hline & Alcohol and drug abuse (Cicchetti and Handley 2019) \\
\hline & Cognitive impairment (Aas et al. 2019) \\
\hline & $\begin{array}{l}\text { Delinquent, violent and other risk-taking behaviors (Mumford } \\
\text { et al. 2019) }\end{array}$ \\
\hline & Depression and anxiety (Rapsey et al. 2019) \\
\hline & $\begin{array}{l}\text { Deliberate food restriction and body-image problem (Bahji et al. } \\
\text { 2019) }\end{array}$ \\
\hline & Feelings of shame and guilt (Baiden et al. 2019) \\
\hline & Poor self-esteem (McDonald et al. 2019) \\
\hline & Post-traumatic stress disorder (Hartley et al. 2016) \\
\hline & Deliberate self-harm and Suicidal behavior (Shapero et al. 2019) \\
\hline \multirow[t]{6}{*}{ Other longer-term health consequences } & Cancer (Henchoz et al. 2019) \\
\hline & Respiratory diseases (Riedl et al. 2019) \\
\hline & Fibromyalgia (Varinen et al. 2019) \\
\hline & Irritable bowel syndrome (Parker et al. 2019) \\
\hline & Ischemic heart disease (Obi et al. 2019) \\
\hline & Reproductive health problems such as infertility (Panisch 2019) \\
\hline
\end{tabular}




\section{Intervention/Therapy}

Child maltreatment tends to trigger a myriad of physical, sexual and reproductive problems in addition to cognitive, emotional and behavioral disorders as shown in Table 2. It might also be advisable for those working in the caregiving profession to be trained in the biopsychosocial approach. Currently, in the Arabian Gulf, cadres of western-trained therapists are involved in helping the victim of child maltreatment. However, there is a lack of substantial research that assesses the effectiveness of these western-based psychotherapeutic interventions. To ensure that such interventions do not perpetuate reification fallacy (Kleinman 1987), ethnographic studies that assess their effectiveness are warranted. A major cultural difference in shame-based societies is that they tend to regard outward expressions of negative emotions as disruptive to group cohesion (Baker and Dwairy 2003). Therefore, individuals who are prone to strong negative emotions are likely to attribute their predicament to supernatural external agencies such as fate, jinn, hassad (an evil spirit that represents contemptuous envy) or sihr (sorcery) (Al-Sinawi et al. 2008). Such idioms of distress are likely to encroach on how the victims of maltreatment might narrate their predicaments. Another manner in which psychological distress is expressed in collective societies such as Oman is as somatic-biological symptoms. While such somatization of negative emotions may be socially accepted, it carries the risk of false diagnosis. This would imply that intrapsychic conflict - often the core psychopathology in western clients seeking psychotherapeutic intervention - would be largely absent here (Baker and Dwairy 2003). An alternative intervention for collective societies such as Oman is 'anthrotherapy' instead of classical psychotherapy tailormade for individualist societies. Anthrotherapy appears to be more conducive to deal with shame-oriented distress that is dependent on social relationships. While anthrotherapy is often recommended for ethnic minorities living in the West, in the present context it might function as a therapeutic process that addresses the "collective consciousness" that is a crucial part of individual identity in collective societies such as Oman. Studies are needed therefore to contemplate the best practice in delivering what is often viewed as a psychological intervention in international best practice.

\section{Conclusion}

Childhood adversity, in the form of child abuse and neglect, has been documented in various parts of the world. Anecdotal and impressionist observation studies in various countries of the Arabian Peninsula indicate that the region is not immune to such practices and it appears that the types and characteristics of child maltreatment are as common in the region as they are international. Not dissimilar to other societies in transition, Oman has recently started to implement an informed approach towards the wellbeing of its children, including ratifying the Convention on the Right of the Child (CRC) stipulated by UN in 1996 which is generally viewed as the global benchmark for safeguarding the wellbeing of children. However, the laws against child abuse often meet resistance at the implementation level. The collective nature of Omani culture based on shame and honor discourages the victims and families to come forward and seek help. 
To avoid disjunction between 'top-down' vs 'bottom-up', that is the discrepancy between the legal system and the actual on-the-ground situation in Oman, sociocultural studies are needed to decipher how child abuse and neglect is perceived in the Omani society, how Omani children are likely to express their distress due to child abuse, in addition to empirical studies on the prevalence of such violations. A balance between prevention and treatment in dealing with the matter is required, and the judicial system should employ a culturally sensitive approach in its oversight, based on new ethnographic research conducted in different parts of Oman. This should help evolve culturespecific, evidence-based legislation that appears to be the way to protect child rights in Oman in a culturally acceptable manner.

\section{Compliance with Ethical Standards}

Conflict of Interest The authors declare that they have no conflict of interest.

\section{References}

Aas, M., Pizzagalli, D. A., Laskemoen, J. F., Reponen, E. J., Ueland, T., Melle, I., Agartz, I., Steen, N. E., \& Andreassen, O. A. (2019). Elevated hair cortisol is associated with childhood maltreatment and cognitive impairment in schizophrenia and in bipolar disorders. Schizophrenia Research, 213, 65-71. https://doi. org/10.1016/j.schres.2019.01.011.

Al Abduwani, J., Sidebotham, P., Al Saadoon, M., Al Lawati, M., \& Barlow, J. (2017). The child abuse potential inventory: Development of an Arabic version. Child Abuse \& Neglect, 72, 283-290. https://doi. org/10.1016/j.chiabu.2017.08.012.

Al Ayed, I. H., Qureshi, M. I., Al Jarallah, A., \& Al Saad, S. (1998). The Spectrum of child abuse presenting to a University Hospital in Riyadh. Annals of Saudi Medicine, 18(2), 125-131. https://doi.org/10.5144 /0256-4947.1998.125.

Al Midfa, A., Al Farsi, B., Bakry, E., Jawad, A., Saleheen, H., Almuneef, M., \& Al-Eissa, M. (2019). Child maltreatment prevention readiness in the United Arab Emirates. Children and Youth Services Review, $100,70-75$.

Al-Adawi, S. (2006). Adolescence in Oman. International encyclopedia of adolescence: A historical and cultural survey of young people around the world (Vol. 2, pp. 713-728). New York: Routledge.

Al-Adawi, S. (2014). Tomorrow's people matters: Evidence for action in Oman. Oman Medical Journal, 29(2), 83-84.

Al-Adawi, S. H., Martin, R. G., Al-Salmi, A., \& Ghassani, H. (2001). Zar: Group distress and healing. Mental Health, Religion \& Culture, 4(1), 47-61. https://doi.org/10.1080/13674670124303.

Al-Adawi, S., Jaju, S., Al-Zakwani, I., \& Dorvlo, A. S. (2011). Culture to culture: Fat-phobia and somatization. In V. R. Preedy, R. R. Watson, \& C. R. Martin (Eds.), Handbook of Behavior, Food and Nutrition (pp. 1457-1473). New York: Springer. https://doi.org/10.1007/978-0-387-92271-3_94.

Alakhzami, M., \& Huang, A. (2020). Individuals with Autism Spectrum Disorders and Developmental Disorders in Oman: An Overview of Current Status. Journal of Autism and Developmental Disorders. https://oi.org/10.1007/s10803-019-04360-y.

Al-Barwani, T. A., \& Albeely, T. S. (2007). The Omani family: Strengths and challenges. Marriage \& Family Review, 41(1-2), 119-142.

Al-Belushi, A. (2004). Gender issues in teacher development: Career choice and commitment in Oman. English Language Teacher Education and Development, 8(8), 1-25.

Al-Eissa, M. A., Saleheen, H. N., Almadani, S., Albuhairan, F. S., Weber, A., Fluke, J. D., Almuneef, M., \& Casillas, K. L. (2016). Determining prevalence of maltreatment among children in the kingdom of Saudi Arabia. Child: Care, Health and Development, 42(4), 565-571. https://doi.org/10.1111/cch.12325.

Alexander, R. C., Levitt, C. J., \& Smith, W. L. (2001). Abusive head trauma. In R. M. Reece \& S. Ludwig (Eds.), Child abuse: medical diagnosis and management (2nd ed., pp. 47-80). Philadelphia: Lippincott Williams \& Wilkins. 
Al-Fayez, G. A., Ohaeri, J. U., \& Gado, O. M. (2012). Prevalence of physical, psychological, and sexual abuse among a nationwide sample of Arab high school students: association with family characteristics, anxiety, depression, self-esteem, and quality of life. Social psychiatry and psychiatric epidemiology, 47(1), 53-66.

Al-Hinai, H. (2014). Female genital mutilation in the Sultanate of Oman [PDF]. http://www.stopfgmmideast. org/wp-content/uploads/2014/01/habiba-al-hinai-female-genital-mutilation-in-the-sultanate-of-oman1. pdf. Accessed 21 Feb 2020.

Alizadeh, H., Applequist, K. F., \& Coolidge, F. L. (2007). Parental self-confidence, parenting styles, and corporal punishment in families of ADHD children in Iran. Child Abuse \& Neglect, 31(5), 567-572. https://doi.org/10.1016/j.chiabu.2006.12.005.

Al-Mahroos, F. T. (2007). Child abuse and neglect in the Arab Peninsula. Saudi Medical Journal, $28(2), 241$.

Al-Mahroos, F., \& Al-Amer, E. (2011). Reported child sexual abuse in Bahrain: 2000-2009. Annals of Saudi Medicine, 31(4), 376-382. https://doi.org/10.4103/0256-4947.83218.

Al-Mannai, H., \& Everatt, J. (2005). Phonological processing skills as predictors of literacy amongst Arabic speaking Bahraini School Children. Dyslexia, 11, 269-291.

Al-Moosa, A., Al-Shaiji, J., Al-Fadhli, A., Al-Bayed, K., \& Adib, S. M. (2003). Pediatricians' knowledge, attitudes and experience regarding child maltreatment in Kuwait. Child Abuse \& Neglect, 27(10), 11611178. https://doi.org/10.1016/j.chiabu.2003.09.009.

Almuneef, M. (2019). Long term consequences of child sexual abuse in Saudi Arabia: A report from national study. Child Abuse \& Neglect. https://doi.org/10.1016/j.chiabu.2019.03.003.

Almuneef, M., Alghamdi, L., \& Saleheen, H. (2016a). Family profile of victims of child abuse and neglect in the Kingdom of Saudi Arabia. Saudi Medical Journal, 37(8), 882-888. https://doi.org/10.15537 /smj.2016.8.14654.

Almuneef, M., Hollinshead, D., Saleheen, H., Almadani, S., Derkash, B., Albuhairan, F., \& Fluke, J. (2016b). Adverse childhood experiences and association with health, mental health, and risky behavior in the kingdom of Saudi Arabia. Child Abuse \& Neglect, 60, 10-17. https://doi.org/10.1016/j. chiabu.2016.09.003.

Almuneef, M., Elchoueiry, N., Saleheen, H. N., \& Al-Eissa, M. (2017). Gender-based disparities in the impact of adverse childhood experiences on adult health: Findings from a national study in the Kingdom of Saudi Arabia. International Journal for Equity in Health. https://doi.org/10.1186/s12939-017-0588-9.

Alnasser, Y., Albijadi, A., Abdullah, W., Aldabeeb, D., Alomair, A., Alsaddiqi, S., \& Alsalloum, Y. (2017). Child maltreatment between knowledge, attitude and beliefs among Saudi pediatricians, pediatric residency trainees and medical students. Annals of Medicine and Surgery, 16, 7-13. https://doi.org/10.1016/j. amsu.2017.02.008.

Al-Saadoon, M., \& Al-Adawi, S. (2019). Informed consent in societies with different ethos of 'selfhood'. Sultan Qaboos University Medical Journal, 19(1), e1-e3. https://doi.org/10.18295 /squmj.2019.19.01.001.

Al-Saadoon, M., Al-Sharbati, M., El Nour, I., \& Al-Said, B. (2012). Child maltreatment: Types and effects: Series of six cases from a University Hospital in Oman. Sultan Qaboos University Medical Journal, 12(1), 97-102. https://doi.org/10.12816/0003094.

Al-Saadoon, M., Al-Farsi, Y. M., Rizvi, S., Al-Sharbati, M., Al-Jabri, A., Almamari, S., Al-Jabri, A., Almamari, S., Al-Baluki, W., \& Al-Adawi, S. (2014). The magnitude and impact of bullying among school pupils in Muscat, Oman: A cross-sectional study. The Scientific World Journal, 2014, 1-10. https://doi.org/10.1155/2014/169737.

Alshekaili, M., Yahya Alkalbani, Y., Walid Hassan, W., Fatima Alsulimani, F., Salim Alkasbi, S., Chan, M. F., \& Al-Adawi, S. (2020). Characteristic and psychosocial consequences of sexually abused children referred to a tertiary care facility in Oman: Sentinel study. Heliyon, 4, e03150. https://doi.org/10.1016/j. heliyon.2019.e03150.

Al-Shidhani, T. A., \& Arora, V. (2011). Cannabis exposure in an Omani child: First case report from Oman. Sultan Qaboos University Medical Journal, 11(4), 511-514.

Al-Sinawi, H., Al-Adawi, S., \& Al-Guenedi, A. (2008). Ramadan fasting triggering Koro-like symptoms during acute alcohol withdrawal: A case report from Oman. Transcultural Psychiatry, 45(4), 695-704. https://doi.org/10.1177/1363461508100791.

Altamimi, D., Almuneef, M., Albuhairan, F., \& Saleheen, H. (2017). Examining the relationship between child maltreatment and school performance in public schools in Saudi Arabia: A pilot study. Scandinavian Journal of Public Health, 45(5), 536-542. https://doi.org/10.1177/1403494817703211.

Al-Tarrah, K., Khashaba, H., Wilson, Y., Al-Fadhli, A., \& Moiemen, N. (2013). Parental authority to refuse acute burn treatment versus the protection our children deserve. Annals of Burns and Fire Disasters, $26(1), 30-35$. 
Althaus, F. A. (1997). Female circumcision: Rite of passage or violation of rights? International Family Planning Perspectives, 23(3), 130. https://doi.org/10.2307/2950769.

Amzat, I. H., Al-Ani, W. T., Ismail, O. H., \& Al Omairi, T. (2017). Women's empowerment and its effect on community development in Oman: Predictive model and indicators for best practices. Community, Work \& Family, 22(3), 338-356. https://doi.org/10.1080/13668803.2017.1367274.

Atiyyah, H. S. (1996). Expatriate acculturation in Arab Gulf countries. Journal of Management Development, 15(5), 37-47.

Bahji, A., Mazhar, M. N., Hudson, C. C., Nadkarni, P., Macneil, B. A., \& Hawken, E. (2019). Prevalence of substance use disorder comorbidity among individuals with eating disorders: A systematic review and meta-analysis. Psychiatry Research, 273, 58-66. https://doi.org/10.1016/j.psychres.2019.01.007.

Baiden, P., Mengo, C., Boateng, G. O., \& Small, E. (2019). Investigating the association between age at first alcohol use and suicidal ideation among high school students: Evidence from the youth risk behavior surveillance system. Journal of Affective Disorders, 242, 60-67. https://doi.org/10.1016/j. jad.2018.08.078.

Baker, K., \& Dwairy, M. (2003). Cultural norms versus state law in treating incest: A suggested model for Arab families. Child Abuse \& Neglect, 27(1), 109-123. https://doi.org/10.1016/s0145-2134(02)00505-7.

Barstow, D. G. (1999). Female genital mutilation: The penultimate gender abuse. Child Abuse \& Neglect, 23(5), 501-510. https://doi.org/10.1016/s0145-2134(99)00017-4.

Beauchamp T.L. (2019). A Defense of universal principles in biomedical ethics. In E. Valdés \& J. Lecaros (Eds.), Biolaw and policy in the twenty-first century: International library of ethics, Law, and the New Medicine (Vol. 78, pp 3-17). Cham: Springer. https://doi.org/10.1007/978-3-030-05903-3 1.

Belwal, R., \& Belwal, S. (2017). Employers' perception of women workers in Oman and the challenges they face. Employee Relations, 39(7), 1048-1065. https://doi.org/10.1108/er-09-2016-0183.

Benedict, R., \& Gennep, A. V. (1978). The Chrysanthemum and the sword: Patterns of Japanese culture. Rain, 24, 14. https://doi.org/10.2307/3032420.

Briere, J., \& Elliott, D. M. (2003). Prevalence and psychological sequelae of self-reported childhood physical and sexual abuse in a general population sample of men and women. Child Abuse \& Neglect, 27(10), 1205-1222. https://doi.org/10.1016/j.chiabu.2003.09.008.

Browning, D. H., \& Boatman, B. (1977). Incest: Children at risk. The American Journal of Psychiatry, 134(1), 69-72. https://doi.org/10.1176/ajp.134.1.69.

Buchweitz, A., Azeredo, L. A., Sanvicente-Vieira, B., Cará, V. M., Esper, N. B., Soder, R. B., da Costa, J. C., Portuguez, M. W., Franco, A. R., \& Grassi-Oliveira, R. (2019). Violence and Latin-American preadolescents: A study of social brain function and cortisol levels. Developmental Science, 22, e12799. https://doi.org/10.1111/desc.12799.

Carolina, M. S., \& Gustavo, L. F. (2003). Epidemiological transition: Model or illusion? A look at the problem of health in Mexico. Social Science \& Medicine, 57(3), 539-550.

Cerrato, J., \& Cifre, E. (2018). Gender inequality in household chores and work-family conflict. Frontiers in Psychology, 9, 1330. https://doi.org/10.3389/fpsyg.2018.01330.

Chesnais, J.-C. (1993). The demographic transition: Stages, patterns, and economic implications: A longitudinal study of sixty-seven countries covering the period 1720-1984. Oxford: Oxford University Press.

Cicchetti, D., \& Handley, E. D. (2019). Child maltreatment and the development of substance use and disorder. Neurobiology of Stress, 10, 100144. https://doi.org/10.1016/j.ynstr.2018.100144.

Cooperman, D. R., \& Merten, D. F. (2001). Skeletal manifestations of child abuse. In R. M. Reece \& S. Ludwig (Eds.), Child abuse: Medical diagnosis and management (pp. 123-156). Philadelphia: Lippincott Williams \& Wilkins.

Croft, J., Heron, J., Teufel, C., Cannon, M., Wolke, D., Thompson, A., Houtepen, L., \& Zammit, S. (2019). Association of trauma type, age of exposure, and frequency in childhood and adolescence with psychotic experiences in early adulthood. JAMA Psychiatry, 76(1), 79. https://doi.org/10.1001 /jamapsychiatry.2018.3155.

Cross, T., \& Mendaglio, S. (1994). Social/emotional needs: Gifted sensitivity to criticism. Gifted Child Today, 17(3), 24-25. https://doi.org/10.1177/107621759401700307.

Dorvlo, A. S., Bakheit, C. S., Al-Riyami, A., Morsi, M., \& Al-Adawi, S. (2006). A study of fertility patterns of ever married women in Oman. Sultan Qaboos University Medical Journal, 6(2), 33-40.

Douglas, E. M. (2016). Testing if social services prevent fatal child maltreatment among a sample of children previously known to child protective services. Child maltreatment, 21(3), 239-249. https://oi. org/10.1007/978-94-017-7583-0_2.

Douki, Z. E., Esmaeili, M. R., Vaezzadeh, N., Mohammadpour, R. A., Azimi, H., Sabbaghi, R., \& Shahhosseini, Z. (2013). Maternal child abuse and its association with maternal anxiety in the sociocultural context of Iran. Oman Medical Journal, 28(6), 404-409. 
Durkheim, E. (1997). The division of labour in society. Trans. W. D. Halls, intro. Lewis A. Coser. New York: Free Press.

Dwairy, M., \& Menshar, K. E. (2006). Parenting style, individuation, and mental health of Egyptian adolescents. Journal of Adolescence, 29(1), 103-117. https://doi.org/10.1016/j.adolescence.2005.03.002.

Edmunds, A. L., \& Edmunds, G. A. (2005). Sensitivity: A double-edged sword for the pre-adolescent and adolescent gifted child. Roeper Review: A Journal on Gifted Education, 27(2), 69-77. https://oi. org/10.1080/02783190509554293.

Eldeeb, N., Halileh, S., Alyafei, K. A., Ghandour, R., Dargham, S., Giacaman, R., Kamal, M., Imseeh, S., Korayem, M., Nasr, S., Mahfoud, Z., Abu-Rmeileh, N., Mahmoud, M. H., Tawfik, H., Lynch, M. A., \& Mian, M. (2016). Child discipline in Qatar and Palestine: A comparative study of ICAST-R. Child Abuse \& Neglect, 61, 63-72. https://doi.org/10.1016/j.chiabu.2016.10.006.

Felitti, V. J., Anda, R. F., Nordenberg, D., Williamson, D. F., Spitz, A. M., Edwards, V., et al. (1998). Relationship of childhood abuse and household dysfunction to many of the leading causes of death in adults. American Journal of Preventive Medicine, 14(4), 245-258. https://doi.org/10.1016/s0749-3797(98 )00017-8.

Fleming, L. C., \& Jacobsen, K. H. (2009). Bullying among middle-school students in low- and middle-income countries. Health Promotion International, 25(1), 73-84. https://doi.org/10.1093/heapro/dap046.

Friesen, M. D., Horwood, L. J., Fergusson, D. M., \& Woodward, L. J. (2017). Exposure to parental separation in childhood and later parenting quality as an adult: Evidence from a 30-year longitudinal study. Journal of Child Psychology and Psychiatry, 58(1), 30-37. https://doi.org/10.1111/jcpp.12610.

Gelbeheri, Mahfoudhi, A., \& Everatt, J. (2009). Dyslexia in the Arab World. Perspectives on Language and Literacy, 35, 9-12.

General Secretariat of the League of Arab States (2010). Arab comparative report on the extent of implementing the recommendations of the study of the Secretary-General of the United Nations to stop violence against children. Department of Family and Childhood - Social Affairs Sector. https://violenceagainstchildren.un.org/sites/violenceagainstchildren.un.org/files/documents/political_ declarations/las_report_final_2010.pdf. Acessed 30 July 2020.

Global Burden of Disease Child and Adolescent Health Collaboration, Kassebaum, N., Kyu, H. H., Zoeckler, L., Olsen, H. E., et al. (2017). Child and adolescent health from 1990 to 2015: Findings from the global burden of diseases, injuries, and risk factors 2015 study. JAMA Pediatrics, 171(6), 573-592. https://doi. org/10.1001/jamapediatrics.2017.0250.

Hall, K. S., Beauregard, J. L., Rentmeester, S. T., Livingston, M., \& Harris, K. M. (2019). Adverse life experiences and risk of unintended pregnancy in adolescence and early adulthood: Implications for toxic stress and reproductive health. SSM - Population Health, 7, 100344. https://doi.org/10.1016/j. ssmph.2018.100344.

Hart, S. N., \& Glaser, D. (2011). Psychological maltreatment - maltreatment of the mind: A catalyst for advancing child protection toward proactive primary prevention and promotion of personal well-being. Child Abuse \& Neglect, 35(10), 758-766. https://doi.org/10.1016/j.chiabu.2011.06.002.

Hartley, S., Johnco, C., Hofmeyr, M., \& Berry, A. (2016). The nature of posttraumatic growth in adult survivors of child sexual abuse. Journal of Child Sexual Abuse, 25(2), 201-220. https://doi.org/10.1080 /10538712.2015.1119773.

Hashim, R., \& Al-Ani, A. (2013). Child physical abuse: Assessment of dental students' attitudes and knowledge in United Arab Emirates. European Archives of Paediatric Dentistry, 14(5), 301-305. https://doi.org/10.1007/s40368-013-0063-2.

Henchoz, Y., Seematter-Bagnoud, L., Nanchen, D., Büla, C., Gunten, A. V., Démonet, J., \& SantosEggimann, B. (2019). Childhood adversity: A gateway to multimorbidity in older age? Archives of Gerontology and Geriatrics, 80, 31-37. https://doi.org/10.1016/j.archger.2018.10.003.

Hillis, S., Mercy, J., Amobi, A., \& Kress, H. (2016). Global prevalence of past-year violence against children: A systematic review and minimum estimates. Pediatrics, 137(3), e20154079.

Islam, M. M. (2012). The practice of consanguineous marriage in Oman: Prevalence, trends and determinants. Journal of Biosocial Science, 44(5), 571-594.

Islam, M. M. (2020). Demographic transition in Sultanate of Oman: Emerging demographic dividend and challenges. Middle East Fertility Society Journal, 25(1), 1-14.

Itzhaky, H., \& York, A. S. (2001). Child sexual abuse and incest: Community-based intervention. Child Abuse \& Neglect, 25(7), 959-972. https://doi.org/10.1016/s0145-2134(01)00249-6.

Jones, L., Bellis, M. A., Wood, S., Hughes, K., McCoy, E., Eckley, L., \& Officer, A. (2012). Prevalence and risk of violence against children with disabilities: A systematic review and meta-analysis of observational studies. Lancet (London, England), 380(9845), 899-907. https://doi.org/10.1016/S0140-6736(12)606928. 
Kassebaum, N., Kyu, H. H., Zoeckler, L., Olsen, H. E., Thomas, K., Pinho, C., et al. (2017). Child and adolescent health from 1990 to 2015: Findings from the global burden of diseases, injuries, and risk factors 2015 study. JAMA Pediatrics, 171(6), 573-592.

Kempe, C. H., Silverman, F. N., Steele, B. F., Droegemueller, W., Silver, H. K., \& Kempe, C. H. (2013). A 50 year legacy to the field of child abuse and neglect. Child Maltreatment, 1, 193-198.

Kenny, M. C. (2004). Teachers' attitudes toward and knowledge of child maltreatment. Child Abuse \& Neglect, 28(12), 1311-1319. https://doi.org/10.1016/j.chiabu.2004.06.010.

Kim, S. Y. (2013). Defining tiger parenting in Chinese Americans. Human Development, 56(4), $217-222$. https://doi.org/10.1159/000353711.

Kiser, L. J., Heston, J., Millsap, P. A., \& Pruitt, D. B. (1991). Physical and sexual abuse in childhood: relationship with post-traumatic stress disorder. Journal of the American Academy of Child and Adolescent Psychiatry, 30(5), 776-783.

Kleinman, A. (1987). Anthropology and psychiatry: The role of culture in cross-cultural research on illness. British Journal of Psychiatry, 151(4), 447-454.

Klika, J. B., Rosenzweig, J., \& Hiner, Z. (2020). Prevention of child sexual abuse. In I. Bryce \& W. Petherick (Eds.), Child sexual abuse: Forensic issues in evidence, impact, and management (pp. 643-656). New York: Academic Press.

Kotch, J. B., Chalmers, D. J., Fanslow, J. L., Marshall, S., \& Langley, J. D. (1993). Morbidity and death due to child abuse in New Zealand. Child Abuse \& Neglect, 17(2), 233-247. https://doi.org/10.1016/0145-2134 (93)90043-5.

Koul, R., Poothrikovil, R., Al-Azri, F., \& Al-Sadoon, M. (2013). Evolution of epileptic encephalopathy in an infant with non-accidental head injury. Neurosciences, 18(3), 264-268.

Lau, A. S., Leeb, R. T., English, D., Graham, J. C., Briggs, E. C., Brody, K. E., \& Marshall, J. M. (2005). Whats in a name? A comparison of methods for classifying predominant type of maltreatment. Child Abuse \& Neglect, 29(5), 533-551. https://doi.org/10.1016/j.chiabu.2003.05.005.

Leeb, R. T., Paulozzi, L. J., Melanson, C., Simon, T. R., \& Arias, I. (2008). Child maltreatment surveillance: Uniform definitions for public health and recommended data elements. PsycEXTRA Dataset. https://doi. org/10.1037/e587022010-001.

Mansour, S. (2017). Spatial concentration patterns of south Asian low-skilled immigrants in Oman: A spatial analysis of residential geographies. Applied Geography, 88, 118-129. https://doi.org/10.1016/j. apgeog.2017.09.006.

Mathews B. (2019) Law's role in preventing, detecting and responding to child sexual abuse: In New International Frontiers in Child Sexual Abuse. Child Maltreatment (Contemporary Issues in Research and Policy), vol 7. Cham: Springer. https://doi.org/10.1007/978-3-319-99043-9 4.

Mcbeth, J., Macfarlane, G. J., Benjamin, S., Morris, S., \& Silman, A. J. (1999). The association between tender points, psychological distress, and adverse childhood experiences: A community-based study. Arthritis \& Rheumatism, 42(7), 1397-1404. https://doi.org/10.1002/1529-0131(199907)42:73.0.co;2-7.

Mcdonald, S., Madigan, S., Racine, N., Benzies, K., Tomfohr, L., \& Tough, S. (2019). Maternal adverse childhood experiences, mental health, and child behaviour at age 3: The all our families community cohort study. Preventive Medicine, 118, 286-294. https://doi.org/10.1016/j.ypmed.2018.11.013.

Merza, A., Al-Saffar, M., Sarhan, M. M., \& Al-Saffar, L. (2013). Reporting child abuse: A survey of primary care physicians in Bahrain. Journal of the Bahrain Medical Society, 24(3), 115-120.

Mintz, G., Etengoff, C., \& Grysman, A. (2017). The relation between childhood parenting and emerging adults' experiences of shame and guilt. Journal of Child and Family Studies, 26(10), 2908-2920. https://doi.org/10.1007/s10826-017-0778-5.

Mogaddam, M., Kamal, I., Merdad, L., \& Alamoudi, N. (2016). Knowledge, attitudes, and behaviors of dentists regarding child physical abuse in Jeddah, Saudi Arabia. Child Abuse \& Neglect, 54, 43-56. https://doi.org/10.1016/j.chiabu.2016.02.004.

Monit Cheung, Needha McNeil Boutte-Queen, (2000) Emotional responses to child sexual abuse: a comparison between police and social workers in Hong Kong. Child Abuse \& Neglect 24 (12):1613-1621

Mumford, E. A., Taylor, B. G., Berg, M., Liu, W., \& Miesfeld, N. (2019). The social anatomy of adverse childhood experiences and aggression in a representative sample of young adults in the U.S. Child Abuse \& Neglect, 88, 15-27. https://doi.org/10.1016/j.chiabu.2018.10.016.

National Centre for Statistics and Information (2016). Millennium development goals: The fourth national report. https:/www.ncsi.gov.om/Elibrary/LibraryContentDoc/ben_Millennium\%20Development\%20 Goals_The\%20Fourth\%20National\%20Report_4cc73fdf-c5a8-4b80-b948-2587ff96cdb3.pdf. Accessed 12 Jan 2020. 
Norman, R. E., Byambaa, M., De, R., Butchart, A., Scott, J., \& Vos, T. (2012). The long-term health consequences of child physical abuse, emotional abuse, and neglect: A systematic review and metaanalysis. PLoS Medicine, 9(11), e1001349. https://doi.org/10.1371/journal.pmed.1001349.

Obi, I. E., Mcpherson, K. C., \& Pollock, J. S. (2019). Childhood adversity and mechanistic links to hypertension risk in adulthood. British Journal of Pharmacology, 176(12), 1932-1950. https://doi. org/10.1111/bph.14576.

Obosi, J. O. (2019). Decentralized governance in the management of urban health care systems in developing countries. Open Journal of Political Science, 09(01), 189-202. https://doi.org/10.4236/ojps.2019.91010.

Osman, O. T., Abbas, A. K., Eid, H. O., Salem, M. O., \& Abu-Zidan, F. M. (2013). Interpersonal violence in the United Arab Emirates. International Journal of Injury Control and Safety Promotion, 21(3), 260-265. https://doi.org/10.1080/17457300.2013.812666.

Osman, O. T., Abbas, A. K., Eid, H. O., Salem, M. O., \& Abu-Zidan, F. M. (2014). Interpersonal violence in the United Arab Emirates. International Journal of Injury Control and Safety Promotion,21(3), 260-265. https://doi.org/10.1080/17457300.2013.812666

Paine, M. L., \& Hansen, D. J. (2002). Factors influencing children to self-disclose sexual abuse. Clinical Psychology Review, 22(2), 271-295.

Panisch, L. S. (2019). Conceptualizations of dissociation and somatization in literature on chronic pelvic pain in women: A scoping review. European Journal of Trauma \& Dissociation, 4, 100093. https://doi. org/10.1016/j.ejtd.2019.01.001.

Parker, C. H., Naliboff, B. D., Shih, W., Presson, A. P., Videlock, E. J., Mayer, E. A., \& Chang, L. (2019). Negative events during adulthood are associated with symptom severity and altered stress response in patients with irritable bowel syndrome. Clinical Gastroenterology and Hepatology, 17, 2245-2252. https://doi.org/10.1016/j.cgh.2018.12.029.

Parreñas, R. (2015). Servants of globalization: Migration and domestic work (2 edition). Stanford: Stanford University Press.

Peyton, R. P., Ranasinghe, S., \& Jacobsen, K. H. (2017). Injuries, violence, and bullying among middle school students in Oman. Oman Medical Journal, 32(2), 98-105. https://doi.org/10.5001/omj.2017.19.

Profanter, A. (2009). Facing the challenges of children and youth with special abilities and needs on the fringes of Omani society. Children and Youth Services Review, 31(1), 8-15. https://doi.org/10.1016/j. childyouth.2008.05.003.

Pupavac, V. (2001). Misanthropy without borders: the international children's rights regime. Disasters, 25(2), 95-112.

Qasem, F. S., Mustafa, A. A., Kazem, N. A., \& Shah, N. M. (1998). Attitudes of Kuwaiti parents toward physical punishment of children. Child Abuse \& Neglect, 22(12), 1189-1202. https://doi.org/10.1016 /s0145-2134(98)00097-0.

Rapsey, C. M., Scott, K. M., \& Patterson, T. (2019). Childhood sexual abuse, poly-victimization and internalizing disorders across adulthood and older age: Findings from a 25-year longitudinal study. Journal of Affective Disorders, 244, 171-179. https://doi.org/10.1016/j.jad.2018.10.095.

Riedl, D., Beck, T., Exenberger, S., Daniels, J., Dejaco, D., Unterberger, I., \& Lampe, A. (2019). Violence from childhood to adulthood: The influence of child victimization and domestic violence on physical health in later life. Journal of Psychosomatic Research, 116, 68-74. https://doi.org/10.1016/j. jpsychores.2018.11.019.

Roser M (2020) "Fertility rate". Published online at OurWorldInData.org. Retrieved from: https://ourworldindata.org/fertility-rate [online resource].

Runyan, D., Wattam, C., Ikeda, R., Hassan, F., \& Ramiro, L. (2002). Child abuse and neglect by parents and other caregivers. In G. K. Etienne, L. L. Dahlberg, J. A. Mercy, A. B. Zwi \& R. Lozano (Eds.), World report on violence and health. Geneva: World Health Organization.

Sadock, B. J., \& Sadock, V. A. (2007). Kaplan \& Sadock: Synopsis of psychiatry: Behavioral sciences/ clinical psychiatry (10th ed.). Philadelphia: Wolters Kluwer.

Sandwick, J. A. (2019). The gulf cooperation council: Moderation and stability in an interdependent world. New York: Routledge.

Scruton, R. (2000). Bring back stigma without it, we become a shameless society-with some disastrous consequences. City Journal, 10(4), 68-75.

Sethi, D., Aldridge, E., Rakovac, I., \& Makhija, A. (2017). Worsening inequalities in child injury deaths in the WHO European region. International Journal of Environmental Research and Public Health, 14(10), 1128. https://doi.org/10.3390/ijerph14101128.

Shamu, S., Shamu, P., Zarowsky, C., Temmerman, M., Shefer, T., \& Abrahams, N. (2019). Does a history of sexual and physical childhood abuse contribute to HIV infection risk in adulthood? A study among post- 
natal women in Harare, Zimbabwe. PLoS One, 14(1), e0198866. https://doi.org/10.1371/journal. pone.0198866.

Shapero, B. G., Farabaugh, A., Terechina, O., Decross, S., Cheung, J. C., Fava, M., \& Holt, D. J. (2019). Understanding the effects of emotional reactivity on depression and suicidal thoughts and behaviors: Moderating effects of childhood adversity and resilience. Journal of Affective Disorders, 245, 419-427. https://doi.org/10.1016/j.jad.2018.11.033.

Silvey, R. (2006). Consuming the transnational family: Indonesian migrant domestic workers to Saudi Arabia. Global Networks, 6(1), 23-40.

Stein, J. A., Leslie, M. B., \& Nyamathi, A. (2002). Relative contributions of parent substance use and childhood maltreatment to chronic homelessness, depression, and substance abuse problems among homeless women: Mediating roles of self-esteem and abuse in adulthood. Child Abuse \& Neglect, 26(10), 1011-1027. https://doi.org/10.1016/s0145-2134(02)00382-4.

Stoltenborgh, M., Van Ijzendoorn, M. H., Euser, E. M., \& Bakermans-Kranenburg, M. J. (2011). A global perspective on child sexual abuse: Meta-analysis of prevalence around the world. Child Maltreatment, 16(2), 79-101.

Tang C. M. (2008). Working toward a conceptual definition of child neglect. Journal of Health and Human Services Administration, 31(3), 356-384.

Trickett, P. K., \& Mcbride-Chang, C. (1995). The developmental impact of different forms of child abuse and neglect. Developmental Review, 15(3), 311-337. https://doi.org/10.1006/drev.1995.1012.

U.S. Department of Health and Human Services (2015). Definitions of child abuse and neglect in federal law. https://www.childwelfare.gov/topics/can/defining/federal/. Accessed 22 Jan 2020.

UN Committee on the Rights of the Child (UNCRC) (2015). Consideration of reports submitted by states parties under article 44 of the convention, combined third and fourth periodic reports of states parties due in 2012: Oman, 28 January 2015, CRC/C/OMN/3-4. Available at: https://www.refworld.org/docid/56a1 edf94.html. Accessed February 22, 2020.

UNESCO Institute for Statistic (2020). Browser by country, Oman. http://uis.unesco.org/country/OM. Accessed 21 Jan 2020.

UNICEF (2010). Charting Progress towards child protection in Sultanate of Oman: Findings of a National Consultative Workshop 27th October 2009. Muscat: United Nations Children's Fund. https://www.ncsi. gov.om/Elibrary/LibraryContentDoc/bar_Situation\%20Analysis $\% 20$ of $\% 20$ Children $\% 20$ and $\% 20$ Women\%20Ar 01f448dc-51a7-4872-a892-01 f0df12e33d.pdf. Accessed from 22 Jan 2020.

United Nations Development Programme (UNDP). (2010). Human development report: 40-year trends analysis shows poor countries making faster development gains. http://hdr.undp. org/sites/default/files/pr1-hdr10-overview-e-rev6.pdf. Accessed 22 Jan 2020.

United Nations. General Assembly. (1988). Resolution no. 43/112. Question of a convention on the rights of the child, 8 December 1988. Annual Review of Population Law, 15(113), 496-497.

Varinen, A., Kosunen, E., Mattila, K., Suominen, S., Sillanmäki, L., \& Sumanen, M. (2019). The association between bullying victimization in childhood and fibromyalgia. Data from the nationwide Finnish health and social support (HeSSup) study based on a sample of 64,797 individuals. Journal of Psychosomatic Research, 117, 48-53.

Walker, L. E. (2016). The Battered Woman Syndrome. Springer Publishing Company.

Walker, L. E. (2017). The battered woman syndrome (4th Edition). New York: Springer Publishing Company.

Ward, J. L., \& Viner, R. M. (2017). The impact of income inequality and national wealth on child and adolescent mortality in low and middle-income countries. BMC Public Health, 17(1), 429. https://doi. org/10.1186/s12889-017-4310-z.

Wikan, U. (1984). Shame and honour: A contestable pair. Man, 19, 635-652.

Woodley, M. A. (2009). Inbreeding depression and IQ in a study of 72 countries. Intelligence, 37(3), $268-276$.

Woon, F. L., \& Hedges, D. W. (2008). Hippocampal and amygdala volumes in children and adults with childhood maltreatment-related posttraumatic stress disorder: A meta-analysis. Hippocampus, 18(8), 729 736.

World Health Organization. (2008). World health report 2008. Primary health care: Now more than ever. Geneva: WHO Press World Health Organization, 2008. World Health Report. 9789241563734.

World Health Organization (2016). Child maltreatment: Fact sheet (2016). http://www.who. int/mediacentre/factsheets/fs150/en/. Accessed 12 Feb 2020.

World Health Organization (2020). Child maltreatment. https://www.who.int/news-room/factsheets/detail/child-maltreatment. Accessed 6 Aug 2020.

Publisher's Note Springer Nature remains neutral with regard to jurisdictional claims in published maps and institutional affiliations. 


\section{Affiliations}

\section{Muna Al-Saadoon ${ }^{1} \cdot$ Manal Al-Adawi $^{2} \cdot$ Samir Al-Adawi ${ }^{2}$}

Muna Al-Saadoon

munasa@squ.edu.om

Manal Al-Adawi

manal.aladawi@gmail.com

1 Department of Child Health, College of Medicine and Health Sciences, Sultan Qaboos University, Muscat, Oman

2 Department of Behavioural Science \& Psychiatry, College of Medicine and Health Sciences, Sultan Qaboos University, P.O. Box 35, Al-Khoudh, 123 Muscat, Oman 